\title{
0 índice de mortalidade das startups brasileiras e a necessidade de políticas públicas para o ecossistema empreendedor
}

O setor empresarial, em seus diversos nichos de atuação, constitui o mais importante pilar para sustentação econômica e social de qualquer nação, e apresenta, como grande desafio, a necessidade de planejamento para o sucesso no processo de inserção no mercado, está ausência tem, como um dos principais reflexos, a alta taxa de mortalidade de empreendimentos nos primeiros meses. Isso tanto pode ocorrer em razão da inviabilidade do empreendimento quanto em decorrência da ausência de um planejamento que considere todas as variáveis e condicionantes para o sucesso e sustentabilidade dos empreendimentos. Neste sentido, é necessária a modernização da legislação empresarial brasileira, priorizando novas perspectivas para o planejamento, a exemplo das incubadoras, que se constituem como espaços importantes na colaboração com o processo de planejamento estratégico de empresas que querem se inserir no mercado com riscos mínimos de insucesso.

Palavras-chave: Políticas públicas; Incubadoras de empresas; Empreendedorismo; Startups.

\section{The mortality rate of Brazilian startups and the need for public policies for the entrepreneurial ecosystem}

\begin{abstract}
The business sector, in its various operating niches, constitutes the most important pillar for the economic and social support of any nation, and presents, as a major challenge, the need for planning for success in the market insertion process, this absence has, as one of the main reflexes, to the high mortality rate of enterprises in the first months. This can occur both due to the unfeasibility of the enterprise and due to the absence of planning that considers all the variables and conditions for the success and sustainability of the enterprises. In this sense, it is necessary the modernization of the Brazilian business legislation, prioritizing new perspectives for the planning, like the incubators, which are important spaces in the collaboration with the strategic planning process of companies that want to enter the market with minimal risks of failure.
\end{abstract}

Keywords: Public policies; Business incubators; Entrepreneurship; Startups.

Topic: Empreendedorismo

Reviewed anonymously in the process of blind peer.
Received: 09/01/2021

Approved: 21/03/2021 lago Ervelee da Silva Lima (iD

Universidade Estadual de Santa Cruz, Brasil

http://lattes.cnpq.br/2675121089522084

http://orcid.org/0000-0003-4346-9987

iagoervelle@gmail.com

Alfredo Dib Abdul Nour (iD

Universidade Estadual de Santa Cruz, Brasil

http://lattes.cnpq.br/1796262889247106

http://orcid.org/0000-0001-8936-5791

aadib@uesc.br

Helen Morais de Albuquerque (iD

Universidade do Norte do Paraná, Brasil

http://lattes.cnpq.br/3936070618446597

http://orcid.org/0000-0002-4742-0235

helenalbu@gmail.com
Referencing this:

LIMA, I. E. S.; NOUR, A. D. A.; ALBUQUERQUE, H. M.. O índice de mortalidade das startups brasileiras e a necessidade de políticas públicas para o ecossistema empreendedor. Revista Brasileira de Administração Científica, v.12, n.1, p.147-157, 2021. DOI: http://doi.org/10.6008/CBPC2179-684X.2021.001.0012 


\section{INTRODUÇÃO}

O índice de mortalidade nas empresas brasileiras é um grave problema que exige uma especial e enérgica atenção dos agentes e órgãos responsáveis pela promoção do desenvolvimento econômico, neste sentido, é necessário investimentos no processo de estruturação destas empresas, especialmente as micro e pequenas, que correspondem a maioria absoluta de empreendimentos, representando uma parcela significativa do Produto Interno Bruto-PIB e que são responsáveis pela geração de empregos no Brasil (FERREIRA et al., 2012). A relevância das micro e pequenas empresas nidifica o impacto destas organizações sobre a vida e finanças da sociedade que tem estas como fonte de renda e que usufruem dos serviços prestados.

Na literatura é salientado que no período do século XXI o cenário empresarial buscava por respostas cada vez mais rápidas para as necessidades do mercado. Desta maneira, as corporações têm função na articulação e desenvolvimento de soluções tecnológicas que venham a solucionar e otimizar os mais diversos processos e necessidades essenciais ao funcionamento da sociedade, com a prestação de serviços que são imprescindíveis aos mais variados setores da economia, contribuindo assim para a necessidade cada vez mais constante de inovação.

Por consequência, surgem novos modelos de empreender e fazer negócios, a exemplo das startups, que podem ser simploriamente definidas como organizações criadas para oferecer serviços inovadores em ambientes de extrema incerteza (RIES, 2012). Além do desafio de inserção no mercado, as startups têm o objetivo de buscar soluções operacionais inovadoras e que promovam a otimização dos serviços já existentes ou até mesmo a criação de novas possibilidades de serviços, tendo ainda o desafio de procurar soluções gerenciais baseadas no planejamento estratégico para escapar do alto índice de mortalidade observado nas empresas brasileiras.

Neste contexto de risco associado à fase inicial das empresas, se faz necessário que estas sejam alicerçadas em uma base organizacional sólida e consistente em seus objetivos de inserção no mercado, para isso, as empresas podem contar com o auxílio das incubadoras, caracterizadas como organizações que oferecem serviços de apoio ao planejamento de empreendimentos em um processo que perfaz desde a préincubação, cuja fase propõe definir as características básicas do empreendimento, até a pós-incubação, etapa que oferece suporte para fixação da empresa no mercado (GARCIA et al., 2012).

As empresas que participam de programa de incubação, visando a inserção mais estratégica e planejada no mercado, garantem uma margem consideravelmente menor de insucesso, pois todo o processo envolve um cuidadoso estudo dos riscos e possibilidades. Sendo assim, os empreendedores devem enxergar as incubadoras como um ponto de apoio importante para aumentar as chances de sucesso de seus empreendimentos, proporcionando benefícios tanto para as próprias empresas incubadas, quanto para a sociedade.

Para isso, deve-se maximizar e aprimorar a gestão dos programas de incubadoras, cumprindo assim com o papel destas organizações na solução das demandas da sociedade e empresas, tendo principalmente 
em vista o cenário brasileiro que apresenta uma alta mortalidade de empresas em seus primeiros meses (FERREIRA et al., 2012; NOGUEIRA et al., 2014; SANTINI et al., 2015). Apesar dos notórios benefícios do processo de incubação para as empresas, as políticas públicas no sentido de aprimoramento destes equipamentos têm se mostrado ineficiente e com necessidade de aprimoramento, neste sentido, este trabalho busca elencar algumas políticas voltadas aos startups e para o ecossistema empreendedor de maneira geral.

\section{REVISÃO TEÓRICA}

\section{Conceitos e evolução: importância das incubadoras para o sucesso dos startups}

O primeiro esboço do que iria se tornar o modelo de incubação que temos hoje surgiu no final da década de 1950, quando um empresário adquiriu as instalações das fábricas da Massey Ferguson em Nova Iorque, passando a sublocar o espaço mediante compartilhamento da estrutura física e de serviços para pequenas empresas se instalarem no local e minimizar os impactos causados pelo fim das atividades da indústria que anteriormente ocupava o espaço (GARCIA et al., 2012).

Ainda que desprovida de arcabouços teórico metodológicos essa iniciativa representou uma inovação na maneira de criar e gerir empresas de forma- norteadora para a sistematização do modelo de incubação que temos hoje, que só vieram a ser sistematizadas e implementadas na década de 1970, quando houveram esforços por parte de universitários da região do Vale do Silício no sentido de garantir aporte teórico para realizar a normatização das incubadoras como suporte para implementação de um novo modelo de gestão visando a disseminação de empreendimentos com caráter inovador (GARCIA et al., 2012).

Ao longo tempo, as incubadoras têm se mostrado como um dos mais promissores instrumentos de suporte ao desenvolvimento estratégico para empresas dos mais variados nichos de negócios em seu estágio inicial de formação, como é constatado na seguinte afirmação:

As incubadoras de empresas foram criadas para auxiliar as empresas, principalmente aquelas que estão em formação. Buscam prepará-las, disponibilizando recursos necessários desde o início de suas atividades, a fim de se tornarem competitivas. Dentre os diversos tipos de incubadoras de empresas instaladas no país, destacam-se: as de base tecnológica, as de setores tradicionais, as de empresas mistas, as de cooperativas, as empresas culturais e as de agronegócios. Cada qual com seus objetivos e peculiaridades. (SOUSA, 2019)

O Brasil foi o país pioneiro na América Latina a sediar iniciativas de incubação de empresas, através da implantação da Fundação Parque de Alta Tecnologia de São Carlos - em 1984 no interior do Estado de São Paulo, ocorreram ainda nessa década a criação de incubadoras nos municípios de Campina Grande (PB), Florianópolis (SC) e no Rio de Janeiro (RJ), sendo posteriormente multiplicadas e expandidas a diversos outros locais, nas variadas regiões brasileiras (GARCIA et al., 2012; SOUSA, 2019).

Vale ainda salientar que o grande desafio posto para as incubadoras no Brasil centra-se na superação do grande índice de mortalidade de empresas, especialmente as micro e pequenas, dado que estas apresentam um alto índice de mortalidade ainda durante os primeiros meses de vida dos empreendimentos, desta maneira, a exemplo de estudos demonstrando que de cada 100 empresas abertas na cidade de São Paulo, 27 não chegam nem ao primeiro ano de vida (FERREIRA et al., 2012), e no Estado do Rio Grande do 
Sul, onde $40 \%$ das empresas de micro e pequeno porte não ultrapassam o primeiro ano (SANTINI et al., 2015).

Tais estatísticas revelam o cenário de mortalidade dentre as pequenas empresas brasileiras em seus primeiros meses de vida e apontam para a necessidade de investimentos em políticas que revertam esta situação, dado que, o fracasso de empresas, sobretudo das startups, representa uma perda no sentido dos empregos diretos e indiretos que poderiam ser criados e de toda uma cadeia de fornecedores que seria beneficiada.

Além da representativa perda no que tange à inovação e tecnologia, está pauta precisa estar dentre as prioridades governamentais para o setor empresarial em razão das perdas econômicas e sociais anteriormente mencionadas e ocasionadas pelo encerramento das atividades de uma empresa. Do ponto de vista da gestão empresarial, outro problema a ser considerado para o alto índice de insucesso se dá em função de erros de planejamento para entrar no mercado, fato este que corrobora ainda mais para a necessidade de incubação desses empreendimentos, pois, as atividades envolvidas durante o processo de incubação possuem um alto potencial para a resolução desta problemática (NOGUEIRA et al., 2014; SOUSA, 2019).

Nesse contexto brasileiro de elevado índice de mortalidade, o modelo empreendedor das startups surge como um novo horizonte para o modelo tradicional das empresas, desta maneira, em uma conceituação sintética, Blank et al. (2012) explana que neste modelo empresarial destacando os seguintes aspectos: "uma startup é uma organização temporária construída para buscar respostas que promovam a obtenção de um modelo de negócio recorrente e escalável”.

Estas características fazem com que, em teoria, as startups sejam ações empreendedoras de caráter bastante simplificadora, pois o objetivo principal é buscar novas alternativas e soluções percebidas nas rotinas de consumo de bens e serviços que possuem algum nicho de inovação, para isso, estas organizações não tem espaço para serem conduzidas em um sistema de gestão tradicional. Para alcançarem seus objetivos, as startups se valem de uma estrutura bastante enxuta e dotada das mais variadas facilidades da tecnologia da informação, de maneira que além da eficiência cria-se uma relação mais estreita entre clientes e prestadores de serviço, que de certa maneira é um aspecto altamente positivo e que deve ser elencado no processo de incubação que se faz indispensável para estes empreendimentos (RIES, 2012).

Apesar do caráter inovador o índice de mortalidade entre as startups também é uma realidade, chegando inclusive em alguns casos a serem maiores do que as micro e pequenas empresas convencionais (NOGUEIRA et al., 2014; RAMOS, 2020). Os motivos para a mortalidade das startups são tão complexos quanto os objetivos destes empreendimentos, no Brasil este modelo de negócio ainda enfrenta um agravante de terem contra si um aspecto que é comum a todo setor empresarial que são os entraves causados pelo excesso de trâmites burocráticos.

O grande agravante desta situação para o sucesso das startups são principalmente ligados aos aspectos regem as relações de trabalho altamente burocratizadas e complexos em relação a outros países, o que acaba por colocar exigir muito destas empresas altamente sensíveis no ecossistema empreendedor, 
tendo em vista que estas são pensadas para terem uma estrutura leve e que proporcione serviços a um valor competitivo, como verificamos na seguinte constatação apresentada por sobre o panorama das startups no Brasil:

A posição de concorrência assimétrica se impõe também aos startups no que tange as propostas referentes às relações de trabalho e colaboração na nova economia. Nesse sentido, trata-se de reconhecer que o argumento de que as startups têm reduzida capacidade de captar e manter talentos, de modo que se busca criar condições de atratividade que as permitam concorrer com empresas de maior porte - não apenas com atuação no Brasil, mas também em face de instituições multinacionais, que, dada a crescente conectividade global, cada vez mais contratam serviços remotos. (RAMOS, 2020)

Sendo assim, podemos apontar que dentre outros fatores, os aspectos relacionados a burocracia como um dos principais complicadores para o pleno desenvolvimento do modelo empresarial das startups brasileiros que mais adiante acaba por implicar na mortalidade destas empresas. Tal fato pode ser observado ao analisarmos a figura 1, onde verificamos o dinamismo temporal no índice na mortalidade das startups no Brasil, na qual, constata-se que por volta de $25 \%$ dos empreendimentos deste gênero no Brasil sequer chegam ao primeiro ano e pelo menos metade das iniciativas empreendedora nos moldes de startup não chegam a completar quatro anos ativas no (NOGUEIRA et al., 2014).

Estes números reportam o quão sério é o problema de não continuidade nas startups e denota a necessidade de reversão deste quadro, para isso uma das ações mais urgentes é a desburocratização de ações empreendedoras, haja visto as problemáticas anteriormente mencionadas e ainda para além disso é preciso considerar que este é um modelo relativamente novo e que, portanto, está aberto a adequação aos diferentes segmentos para os quais os empreendimentos estarão voltados.

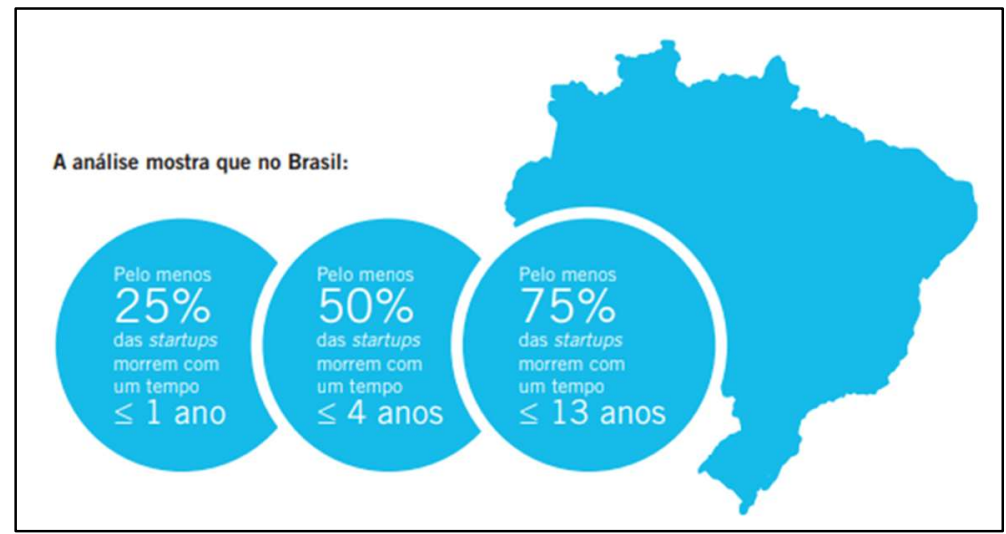

Figura 1: Tempo médio de funcionamento das startups no Brasil. Fonte: Nogueira et al. (2014).

\section{A incubação como fator diferencial para o sucesso das startups}

A incubação de um empreendimento é um processo ainda pouco disseminado entre os que buscam empreender no Brasil, tendo sua utilização ainda bastante restrita, atuando em conjunto com as startups e com pouca inserção nas iniciativas empreendedoras de micro e pequenas empresas convencionais, fato este que representa uma grande perda do ponto de vista do planejamento estratégico para os empresários que não participam dos processos de incubação como primícias para seus negócios.

Apesar de ambos os assuntos, tanto startups quanto incubação de empresas serem campos de estudo relativamente novos e em desenvolvimento a incubação é um modelo de gestão empresarial que traz 
amplos benefícios para o sucesso das empresas, que por sua vez também trará vantagens à sociedade como na geração de empregos.

O processo de incubação pode ser dividido em três etapas: pré-incubação, na qual, é concebido e analisado a viabilidade do projeto; incubação, que é a fase em que a empresa recebe o suporte para colocar em prática o plano de negócios feitos na etapa anterior e pós-incubação, quando as ações são voltadas para a consolidação no mercado mediante a continuidade do relacionamento com a incubadora através de ações de assessoria. Não obstante destas etapas parecerem simples para incubação existem diversos meandros que influenciam direta e indiretamente no sucesso das startups a exemplo de um diagnóstico feito por Nogueira et al. (2014) com 221 empreendimentos, os quais 130 ainda em operação e 91 de startups que já tinham encerrado as atividades. Foi possível fazer uma série de constatações em relação ao tempo de permanência no mercado, o número de sócios como um fator de risco para a sobrevivência da startup ao notarem que quanto maior o número de sócios trabalhando na empresa, aumenta-se consideravelmente risco de descontinuidade (NOGUEIRA et al., 2014). Cabendo também considerar a seguinte explanação:

Sendo assim, podemos constatar que a incubação é um fator de impacto positivo, mas existem alguns outros a serem observados pelo empreendedor em seu ramo de negócios, inclusive os que estão fora do ambiente de controle da incubação, mas que se relacionam diretamente com a possibilidade de sucesso ou inviabilização da empresa. Para isso, a gestão das atividades de incubação deve ser feita considerando as características do nicho de negócio que a startup vai se inserir como um todo, o que se constitui em um grande desafio e deve ser conduzido nos mais rígidos padrões de ética, de maneira que o retorno obtido pelas empresas sejam satisfatórios e capazes de manter a estabilidade no mercado.

Estes aspectos reforçam o papel estabilizador das incubadoras para os primeiros momentos das empresas no mercado, com especial enfoque na capacitação do empreendedor para conhecer seu próprio negócio de maneira assertiva no seu ramo de atuação, no qual, pretende-se adentrar de maneira que podemos ainda elencar as contribuições a seguir:

Portanto, ressalta que as incubadoras contribuem na formação da capacidade gerencial dos empresários e na incorporação de tecnologia aos produtos e processos produtivos da empresa, estimulando o empreendedorismo e divulgando a possibilidade de se iniciar um negócio próprio, com chances reais de êxito. Daí a importância de estimular ações que gerem ambientes de inovação e empreendedores, como ocorrem em alguns modelos organizacionais como as incubadoras de empresas. (SOUSA, 2019)

Posteriormente ao período de incubação, as empresas ganham certa autonomia e são graduadas para avançarem desfrutando do suporte obtido na incubadora nos mais diversos aspectos, como o uso compartilhado de plantas industriais e instalações físicas, além do apoio de recursos humanos altamente qualificados, acesso a equipamentos e ferramentas administrativas, transferência tecnologia e diversas outras ferramentas que dificilmente seriam encontradas fora do ambiente de incubação (OLIVEIRA et al., 2018).

Dados da Associação Nacional de Entidades Promotoras de Empreendimentos Inovadores ANPROTEC, apresentados no Quadro 1 revelam a dimensão de 384 incubadoras no Brasil, com o total de 2640 empresas já incubadas, mais de 16 mil empregos diretos gerados e 2500 empresas graduadas com 
faturamento médio estimado em mais de 4 bilhões de reais. Este cenário verificado no início da década dimensiona a importância das incubadoras de empresas veem ganhando para o ecossistema empreendedor brasileiro, de maneira que tais resultados chamam atenção e que fazem crer que este mecanismo não pode ser deixado de ser levado em conta na elaboração das políticas públicas de empreendedorismo.

Quadro 1: Dados sobre os resultados das incubadoras de empresas no Brasil.

\begin{tabular}{|l|l|}
\hline Incubadoras & 384 \\
\hline Incubadoras existentes & 2.640 \\
\hline Empresas incubadas & Mais de 16.000 \\
\hline Empregos diretos gerados & 2.500 \\
\hline Empresas graduadas & 4,1 bilhões de reais \\
\hline Faturamento médio das empresas & 29.000 \\
\hline Empregos indiretos gerados & \\
\hline
\end{tabular}

Os resultados apontados no quadro acima fazem ainda consolidar a eficiência da estratégia de incubação para o ecossistema empreendedor neste setor da economia e ascende ainda como um indicador de tendências futuras para empreendedores que buscam maximizar as chances de obter sucesso em seus negócios, a partir da adesão ao sistema de incubação que que tem se mostrado altamente eficiente e com prospeç̧ões futuras bastantes animadores, principalmente no quando comprado aos elevados índices de mortalidade entre as micro e pequenas empresas brasileiras desenvolvidas fora do ambiente de incubação (NOGUEIRA et al., 2014; OLIVEIRA et al., 2018; SOUSA, 2019).

\section{METODOLOGIA}

Essa pesquisa é de natureza aplicada de caráter exploratório descritivo (GIL, 2010), de maneira que que buscou-se verificar e proporcionar um maior arcabouço acerca do assunto a partir da construção de um referencial teórico. O levantamento de dados é bibliográfico e de análise qualitativa.

Baseado nisso esta etapa foi subdivida em dois tópicos, o primeiro com o referencial teórico sobre o conceito, evolução e importância das incubadoras (3.1) e no seguinte a pesquisa tratou da incubação como fator diferencial para o sucesso das startups (3.2). Ambos os tópicos construídos a partir da seleção de artigos, teses, dissertações e monografias selecionados de maneira randômica, tendo como único parâmetro a abordagem de forma consistente dos assuntos tratados nos tópicos.

No segundo momento foi realizado uma pesquisa exploratória para cronologicamente verificarmos a evolução e estado da arte da legislação brasileira e apontar aspectos qualitativos (MESQUITA et al., 2014) a respeito políticas públicas para as organizações inseridas no ecossistema empreendedor a partir da Lei $n$. 10.973/2004, destacando as características que exercem influência na regulamentação e desenvolvimento das startups no Brasil.

\section{RESULTADOS E DISCUSSÃO}

\section{Diagnóstico das políticas públicas para o ecossistema empreendedor das startups}

No que se refere políticas públicas para o ecossistema empreendedor brasileiro, podemos dizer que um grande marco foi a Lei n. 10.973/2004, que dispõe sobre incentivos à inovação e à pesquisa científica e 
tecnológica, o que levou a ser considerada como o marco regulatório para a inovação no Brasil e significou um enorme avanço para a modernização da política de empreendimentos inovadores no país, como podemos verificar nas seguintes considerações:

Pode-se afirmar que a Lei n.o 10.973/2004 está orientada para: a criação de um ambiente propício a parcerias estratégicas entre universidades, institutos tecnológicos e instituições privadas; estimular a participação de instituições de ciência e tecnologia no processo de inovação; incentivar a transferência de tecnologia das universidades para o setor produtivo; possibilitar autorizações para a incubação de empresas no espaço público e a possibilidade de compartilhamento de infraestrutura, equipamentos e recursos humanos, públicos e privados, para o desenvolvimento tecnológico e a geração de processos e produtos inovadores; possibilitar a concessão de recursos financeiros. (OLIVEIRA et al., 2013)

Posto isso, podemos verificar que no que se refere a políticas públicas, o trade empreendedor de inovação significou um importante marco do ponto de vista regulatório e operacional, devido a consistência no que tange a infraestrutura oferecida para o ecossistema empreendedor se desenvolver, inclusive ao versar sobre as incubadoras e defini-las como organizações estratégicas para o ambiente de inovação atreladas a estruturas como: instituições Científica, Tecnológica e de Inovação (ICT), Núcleos de Inovação Tecnológica (NIT), fundações de apoio, parques e polos tecnológicos (BRASIL, 2004; OLIVEIRA et al., 2013).

Tendo em vista a característica e importância da Lei n. 10.973/2004 para o ecossistema de inovação, foi selecionada está e mais 4 (Quadro 2) que também contribuem para o nicho empreendedor das startups a partir do estimulo ao desenvolvimento cientifico e tecnológico, simplificação de normativa, criação e atualização de novas subsequentes as de 2004 presentes na Lei complementar no 123/2006, Lei no 13.243/2016 e a Lei complementar 167/2019 detalhadas no quadro abaixo.

Quadro 2: Legislações com influência no ecossistema das startups.

\begin{tabular}{|l|l|l|}
\hline Lei & Ementa & Ano \\
\hline Lei no 10.973 & Dispõe sobre incentivos à inovação e à pesquisa científica e tecnológica no ambiente produtivo & 2004 \\
\hline $\begin{array}{l}\text { Lei complementar № } \\
123\end{array}$ & Institui o Estatuto Nacional da Microempresa e da Empresa de Pequeno Porte & 2006 \\
\hline LEl № 13.243 & $\begin{array}{l}\text { Atualiza a política de estímulos ao desenvolvimento científico, à pesquisa, à capacitação } \\
\text { científica e tecnológica e à inovação }\end{array}$ & 2016 \\
\hline $\begin{array}{l}\text { Lei Complementar № } \\
167\end{array}$ & Dispõe sobre a política nacional para Empresa Simples de Crédito (ESC) & 2019 \\
\hline
\end{tabular}

Ao analisarmos as ementas do quadro acima verificamos que uma política relevante, com reflexos diretos no ecossistema das startups foi a lei complementar $n=123 / 2006$, que regulamenta e caracteriza o micro e pequenas empresas-MPE, refletindo diretamente nas startups justamente pelo caráter de leveza destes empreendimentos que têm o objetivo de solucionarem questões através de inovação tecnológica tendo a estrutura mais enxuta possível (RIES, 2012). Em função destas características podemos dizer que toda startup é concebida em sua fase de ideação ou pré-incubação como um micro ou pequena empresa, estando, portanto, enquadrada nesta legislação, que podemos entender como um esforço governamental principalmente voltado para a formalização dos empreendedores que atuam nesse setor, no entanto, os esforços precisam avançar mais na direção ao fomento destas iniciativas, como podemos conferir na seguinte argumentação:

Desde 2006 o Brasil está em um processo de constante transformação no que se refere a 
práticas de políticas públicas direcionadas a regulamentação das MPEs. A ascensão da Lei geral das Microempresas e empresas de pequeno porte e a criação do simples nacional contribui efetivamente na desburocratização e formalização dos microempreendedores, mas o estimulo ao empreendedorismo não se resume apenas ao ambiente regulatório, é necessário explorar as vertentes ligadas ao desenvolvimento e fomento da inovação, fator relevante para a criação de negócios de alto impacto. (MELZANI et al., 2018)

Desta maneira, podemos constatar que embora tenha havido um relativo entendimento e esforço governamental a respeito da necessidade de avanço no entendimento legal para suporte às MPEs, de maneira geral, ainda há a necessidade notória de investimento em ações indispensáveis para êxito dos agentes empresariais envolvidos nesse ecossistema. Para as empresas convencionais, este cenário é ainda pior que no seguimento das startups e de outras bases tecnológicas, já que não há uma política nacional consistente para o seguimento das convencionais. Em contraponto, no que tange às empresas de base tecnológica e de inovação, tem cada vez mais surgido caminhos voltados para o aporte de investimentos, como é exemplificado a seguir:

Em 2006, a FINEP lançou o Programa Inovar Semente, com a meta de criar fundos para investir exclusivamente em empresas inovadoras de pequeno porte. A FINEP dispunha de aproximadamente $\mathrm{R} \$ 300$ milhões para apoiar em seis anos cerca de 300 empreendimentos inovadores, com aportes que variavam entre $\mathrm{R} \$ 500$ mil e $\mathrm{R} \$ 1$ milhão. Tratava-se de capital fornecido a uma empresa em estágio pré-operacional, muitas vezes ainda dentro de incubadoras e universidades, diferenciando-se dos demais fundos apoiados pela FINEP, que atendiam majoritariamente a empresas em expansão. (RONCARATTI, 2018)

Estes fatos apontam para a necessidade de ampliação da política de assistência ao desenvolvimento das MPEs como um todo, tanto para as empresas convencionais, quanto a ampliação das ações de incubação para as startups e outras do segmento de inovação tecnológica.

A Lei no 13.243/2016 alterou a 10.973/2004, atualizando a política de estímulos ao desenvolvimento científico, pesquisa, capacitação científica e tecnológica e à inovação, na qual, a grande contribuição desta legislação para o ecossistema empreendedor de inovação ficou por conta da tratativa mais robusta sobre as incubadoras como instrumento essencial para a política de inovação empresarial.

O conteúdo da Lei 13.243, antes de mais nada tem um caráter descomplicador e de incentivo a construção de parcerias interinstitucionais em prol do desenvolvimento tecnológico e inovador, isso fica nítido ao constatarmos a regulamentação de ações como a permissão para instituições de ensino e pesquisa partilhem seus recursos humanos e tecnológicos para fins de atividade de inovação, condicionando apenas que não haja prejuízos à atividade finalística da instituição detentora do recurso (BRASIL, 2016; PEREIRA, 2018).

A Lei complementar 167/2019, uma das mais recentes para o ecossistema empreendedor das startups trouxe novidades no que tange a implementação do regime especial de abertura e fechamento de empresas o (Inova Simples), e também a criação de um regime especial para contratação de crédito de baixo custo por empreendedores do ecossistema das MPEs, denominado como Empresa Simples de Crédito (ESC).

O regime especial de abertura e fechamento de empresas previsto no Inova Simples garante na legislação a agilidade necessária tão característica ao ramo das startup , como podemos verificar no terceiro parágrafo do Art.65-A: 
§ 3ㅇ O tratamento diferenciado a que se refere o caput deste artigo consiste na fixação de rito sumário para abertura e fechamento de empresas sob o regime do Inova Simples, que se dará de forma simplificada e automática, no mesmo ambiente digital do portal da Rede Nacional para a Simplificação do Registro e da Legalização de Empresas e Negócios (Redesim), em sítio eletrônico oficial do governo federal, por meio da utilização de formulário digital próprio, disponível em janela ou ícone intitulado Inova Simples. (BRASIL, 2019)

Apesar de parecer uma determinação relativamente simples, estas previsões garantem uma especial agilidade nos trâmites regulatórios, de maneira que vem a simplificar e desburocratizar, estimulando principalmente quem busca iniciar um empreendimento, de maneira rápida e adaptada ao estilo de vida informatizado dos dias atuais.

\section{CONCLUSÕES}

No cenário de avanço da globalização e rearranjo nas demandas sociais por serviços compatíveis na era digital, as startups surgem como fruto do nosso avanço no posicionamento da divisão internacional do trabalho, onde cada vez mais as corporações avançam em territórios antes inimagináveis aumentado a dinamização da economia. Por sua vez, as corporações e seus investidores ainda se veem expostos a um alto risco em seus negócios, que de certa maneira são investimentos com alto potencial de impacto na sociedade, podendo vir a se beneficiar direta ou indiretamente do pleno funcionamento das empresas que atuam nesse nicho de soluções inovadoras agregada a seu plano corporativo de gestão.

Alcançado o êxito, um desafio que deve ser encampado pelas startups deve ser a gestão pautada na Responsabilidade Social Empresarial que é um modelo que deve ser gerido com muita responsabilidade e compromisso no âmbito da sociedade, pois estes representam uma das grandes esperanças para a sociedade que também demanda a atuação do setor privado, principalmente no contexto brasileiro onde há grandes assimetrias e abismos socioeconômicos. Sendo assim, cabe também aos gestores um olhar sensível aos anseios da sociedade, compreendendo seu papel social que precisa ser gerido com responsabilidade. Podendo inclusive, que estas iniciativas venham por meio das startups com ideias inovadoras promover solução de questões do gênero.

Tendo em vista o cenário atual, fortalece ainda mais a necessidade de contribuição do setor de inovação para com a sociedade de maneira geral, inovação está encontrada em startups. No entanto dada as características deste tipo de empreendimento, há a necessidade de apoio como o oferecido por incubadoras de forma a aumentar a chances de sucesso destes empreendimentos.

\section{REFERÊNCIAS}

BLANK, S.; DORF, B.. Startup: Manual do Empreendedor. Rio de Janeiro: Alta Books, 2012.

BRASIL. Lei n.10.973 de 2 de dezembro de 2004. Dispõe sobre incentivos à inovação e à pesquisa científica e tecnológica no ambiente produtivo. Brasília: DOU, 2004.

BRASIL. Lei n.123 de 14 de dezembro de 2006. Institui o Estatuto Nacional da Microempresa e da Empresa de Pequeno Porte Brasília: DOU, 2006.
BRASIL. Lei n.13.243 de 11 de janeiro de 2016. Dispõe sobre estímulos ao desenvolvimento científico, à pesquisa, à capacitação científica e tecnológica e à inovação. Brasília: DOU, 2016.

BRASIL. Lei Complementar n.167 de 24 de abril de 2019. Dispõe sobre a Empresa Simples de Crédito (ESC). Brasília: DOU, 2019. 
FERREIRA, L.; OLIVA, F. L.; SANTOS, S. A.; GRISI, C. C. H.; LIMA, A. C.. Análise quantitativa sobre a mortalidade precoce de micro e pequenas empresas da cidade de São Paulo. Revista Gestão \& Produção, São Carlos,

v.19, n.4, p.811-823, 2012. DOI:

https://doi.org/10.1590/S0104-530X2012000400011

GARCIA, Q.; TERRA, B.. A importância das incubadoras na criação e desenvolvimento de empresas inovadoras de base tecnológica: um estudo de caso do Instituto Gênesis da PUC RIO e da empresa Minds at work. Revista Polêmica, v.10, n.2, p.223-245, 2012.

\section{GIL, A.. Como elaborar projetos de pesquisa. 5 ed. São} Paulo: Atlas, 2010.

NOGUEIRA, V.; ARRUDA, C.. Causas da Mortalidade de Startups Brasileiras. Revista da Fundação Dom Cabral, v.25, p.12, 2014.

OLIVEIRA, F.; FARHAT, C.; CORREA, L.. A democratização do sistema brasileiro de fomento às inovações tecnológicas no âmbito da Lei 10.973/2004. Revista Ética e Filosofia Política, v.1, p.47-56, 2013.

OLIVEIRA, P.; TERENCE, A.. Os períodos de incubação e pósincubação das empresas de base tecnológica sob a ótica do gestor da incubadora: benefícios, dificuldades e diferenciais. Revista Livre de Sustentabilidade e Empreendedorismo, v.3, n.1, p.176-204, 2018.

PEREIRA, S.. Complexo Econômico Industrial da Saúde: os reflexos jurídicos dos estímulos ao desenvolvimento tecnológico previstos na Lei no 13.243/2016. Caderno IberoAmericano de Direito Sanitário, Brasília, v.7, n.1, p.96-110, 2018.
RAMOS, L.. 0 papel das políticas públicas federais para o desenvolvimento do ecossistema de empreendedorismo inovador no Brasil: breve revisão de iniciativas em curso. Monografia (Especialização em Gestão Pública) - Escola Nacional de Administração Pública, Brasília, 2020.

RIES, E.. A startup enxuta: como os empreendedores atuais utilizam a inovação contínua para criar empresas extremamente bem-sucedidas. São Paulo: Lua de Papel, 2012.

RONCARATTI, L. S.. Difusão e inovação em políticas públicas no Brasil: uma análise comparativa dos programas de incentivos a startups. 2018. Tese (Doutorado em Ciência Política) - Universidade de Brasília, Brasília, 2018.

SANTINI, S.; FAVARIN, E. V.; NOGUEIRA, M. A.; OLIVEIRA, M. L.; RUPPENTHAL, J. E.. Fatores de mortalidade em micro e pequenas empresas: um estudo na região central do Rio Grande do Sul. Revista Eletrônica de Estratégia \& Negócios, v.8, n.1, p.145-169, 2015.

SOUSA, M.. A importância das incubadoras de empresas para o desenvolvimento do empreendedorismo no brasil. Revista Gestão em foco, v.11, p.1-10, 2019.

MELZANI, T.; DURIGAN, L.; BRUNI, R.; SANTOS, B.; DUARTE, D.. O ambiente das micros e pequenas empresas no brasil e o ecossistema empreendedor de alto impacto: porque o empresário brasileiro possui dificuldades em inovar?. Revista Gestão em foco, v.11, p.636-655, 2019.

MESQUITA, R.; MATOS, F.. A abordagem qualitativa nas ciências administrativas: aspectos históricos, tipologias e perspectivas futuras. Revista Brasileira de Administração Científica, v.5, n.1, p.7-22, 2014.

A CBPC - Companhia Brasileira de Produção Científica (CNPJ: 11.221.422/0001-03) detém os direitos materiais desta publicação. Os direitos referem-se à publicação do trabalho em qualquer parte do mundo, incluindo os direitos às renovaç̃̃es, expansões e disseminações da contribuiç̃o, bem como outros direitos subsidiários. Todos os trabalhos publicados eletronicamente poderão posteriormente ser publicados em coletâneas impressas sob coordenação da Sustenere Publishing, da Companhia Brasileira de Produção Científica e seus parceiros autorizados. Os (as) autores (as) preservam os direitos autorais, mas não têm permissão para a publicação da contribuiç̃ão em outro meio, impresso ou digital, em português ou em tradução. 